\title{
Power quality improvement using dynamic voltage restorer in electrical distribution system: an overview
}

\author{
Ali Basim Mohammed ${ }^{1}$, Mohd Aifaa Mohd Ariff ${ }^{2}$, Sofia Najwa Ramli ${ }^{3}$ \\ ${ }^{1,2}$ Faculty of Electrical and Electronic Engineering, University Tun Hussein Onn Malaysia, Malaysia \\ ${ }^{3}$ Faculty of Computer Science and Information Technology, Universiti Tun Hussein Onn Malaysia, Malaysia
}

\begin{abstract}
Article Info
\section{Article history:}

Received Feb 20, 2019

Revised May 17, 2019

Accepted Jul 30, 2019

\section{Keywords:}

Cyber-physical system

Dynamic voltage restorer

Power quality

Technological review

Voltage compensation

Voltage sag/swell

ABSTRACT

This paper represents a review of the dynamic voltage restorer for power quality improvement in the electrical distribution system. Over the past 50 years, issues concerning power quality have steadily increased, to prevent the effect of the voltage disturbances, some of the devices are put as a solution to these problems such as distribution static compensator (D-STATCOM), solid-state transformer (SST), and uninterruptible power supply (UPS), dynamic voltage restorer (DVR). The DVR is one of the economic solutions to overcome the voltage disturbances like voltage sag/swell and harmonics. It is widely used to mitigate the voltage disturbances in the power distribution system, especially in the medium and low distribution networks. This paper aims to review the implementation of the DVR in the system integrated with renewable energy resources. This is important because the future of electricity business is moving towards renewable energy and also provides a thorough discussion of the typical components, controllers, compensation methods, and the application of DVR. The extensive review of the technology aims to ease and speed up the development and the advancement of the DVR in the near future.
\end{abstract}

Copyright (C) 2020 Institute of Advanced Engineering and Science. All rights reserved.

\section{Corresponding Author:}

Mohd Aifaa bin Mohd Ariff,

Faculty of Electrical and Electronic Engineering,

University Tun Hussein Onn, Batu Pahat, Johor, Malaysia.

Email: aifaa@uthm.edu.my

\section{INTRODUCTION}

The significance of power quality is something that cannot be compromised between customers and power utility companies because it dictates the benefits in the ever-competitive trade arena. The quality of power delivered to the customer is an asset for the utility company. Voltage disturbance and various power quality issues may cause damage to electrical and electronic appliances. Thus, many efforts have been considered to ensure that the quality of the voltage magnitude and frequency are within the allowable tolerance to deliver a viable quality of power to the user [1]. There are various power quality issues that exist in the system, like voltage swelling, sagging, harmonic, and service interruption. Of all the voltage issues, voltage sag and swell are the critical kinds of disturbance because it affects the performance of the load in the system, especially the sensitive loads.

In order to mitigate the impact of the voltage and power quality disturbance to the system, several methods have been proposed and utilized in practice. The method such as D-STATCOM, SST, UPS, and DVR are used to compensate for the voltage difference between normal and disturbed operating conditions. The DVR is considered as the better solution among all devices in mitigating the voltage sag and swell due to its high-performance as compared to others [2]. Moreover, DVR provides a cost-effective solution compared to other devices [3]. DVR is commonly installed between a network and a sensitive load through a transformer that provides the supplementary voltage supply to compensate voltage instabilities that may cause damages to appliances [4]. 
There are many review papers on the power quality improvement technique in the literature. The authors in [5] focus on the discussion of the UPS circuit, topologies, configuration, and corresponding control algorithm to provide electricity during power shortage. On the other hand, the study reported in [6] provides a review of the application of D-STATCOM during power system operation. It discusses a wide spectrum of circuit topologies and architecture, and the control techniques available in the literature. Moreover, this paper compares the various implementation of D-STATCOM in practice focusing on the utilization for power quality improvement, especially on harmonic filtering and power factor correction. Next, the author in [7] provides a systematical review on the technological development of SST for electrical distribution system application. This review focuses on four critical areas of SST application, including high power and highfrequency transformer, ac to ac converter topologies, and high-voltage power devices. Consequently, the implementation of the DVR for power quality improvement is discussed in [8]. This paper provides an extensive literature survey on the performance, the available control techniques, and the compensation strategies of DVR to improve the quality of power delivered to the user. Then, the studies reported in [9] also provides a review on the DVR implementation in practice. However, this paper focuses on compensation methods and provide a detailed comparison between these techniques. Similarly, the author in [10] provides a comprehensive study on DVR as well. Nevertheless, the focal point of the discussion revolves around the power circuit topologies and control strategies. A review of different types of AC-AC converter based DVR is provided in [11], by utilizing this converter can eliminate the dc storage, leads to reducing in size, weight and cost of the DVR. However, all these review papers do not focus on the implementation of DVR in the system with large renewable energy integration.

This paper represents a review of the dynamic voltage restorer for power quality improvement in the electrical distribution system and the DVR implementation in the system with renewable energy resources. This is important because the future of the electricity business is moving towards renewable energy [12]. Since the role of DVR is crucial to mitigate the voltage stability related disturbance in the system, it is critical to study the implementation of DVR on such system. Despite covering the latest technology update on the DVR development, this paper also discusses the typical components, controllers, compensation methods and the applications of the DVR

\section{THE DYNAMIC VOLTAGE RESTORER}

This section discusses the typical construction of the DVR used in practice. The DVR is a custom power device used in practice to compensate for the voltage sagging, swelling, and harmonic in the distribution network [13]. It is very critical to the operation of the sensitive load [14]. The primary function of a DVR is to detect the voltage disturbance in the system and inject necessary voltage to recover the system voltage back to its normal operating level. injecting voltage to inconstant input to ensure voltage quality for appliances [15].

\section{THE DVR POWER CIRCUIT}

A DVR power circuit comprises four essential aspects, namely, a voltage injection transformer, VSI, low-pass filters, and a device to store DC energy [16], as shown in Figure 1. The descriptions of each DVR components are tabulated in Table 1.

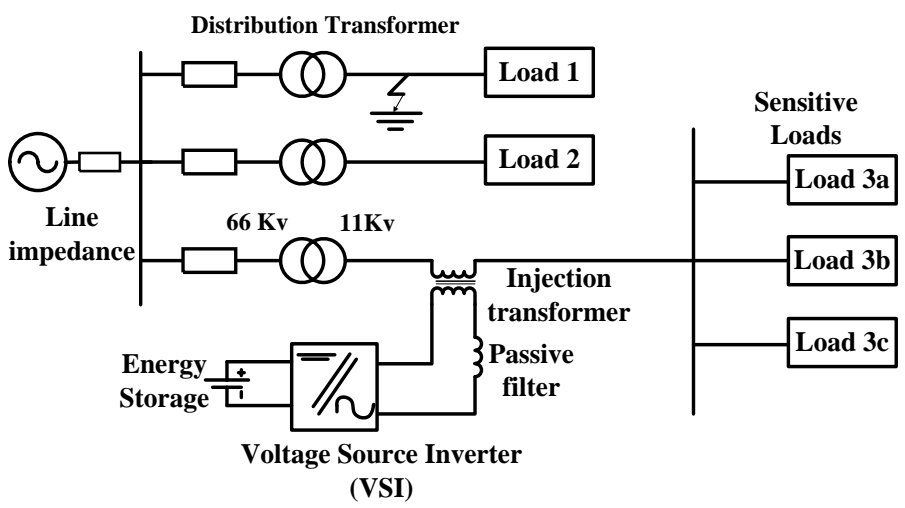

Figure 1. The typical power circuit of a DVR 
Table 1. The descriptions of DVR's components

\begin{tabular}{cl}
\hline Component & Discussion \\
\hline Energy storage & To supply the required energy to compensate the voltage in the system (e.g., supercapacitors, batteries with \\
superconducting magnetic energy storage, lead-acid, and flywheel.
\end{tabular}

\section{DVR COMPENSATION METHODS}

For voltage injection, phase angle and magnitude are crucial aspects in controlling a DVR. The required voltage supply could be met by employing three methods of compensation. The basic approaches for control include in-phase, pre-sag, and minimal energy compensation techniques [20].

\subsection{Compensation via Pre-Sag}

Figure 2 illustrates the pre-sag compensation technique utilized for the DVR application. This method compensates the variance of sagging voltage with pre-sag voltage by restoring the magnitude and the phase of the voltage prior to the occurrence of the voltage sag [21]. In the figure, the voltage of the system prior to the disturbance are represented by $V_{\text {pre-sag }}$. Following the voltage disturbance, the voltage and the phase angle decreased to $V_{s a g}$ and $\theta_{s a g}$, respectively. In order to compensate this sag, this method injects the voltage magnitude $V_{D V R}$ and the phase angle $\theta_{D V R}$ to the system to compensate for the decrement of the $V_{s a g}$ and $\theta_{\text {sag }}$ during the disturbance, respectively. This pre-sag compensation method requires a relatively higher magnitude of voltage injection as compared to other approaches. Hence, the active power requirement is relatively high at the occurrence of voltage sagging. Typically, this approach is applied to the appliances that are sensitive to the phase angle shift, e.g., thyristor-type converter.

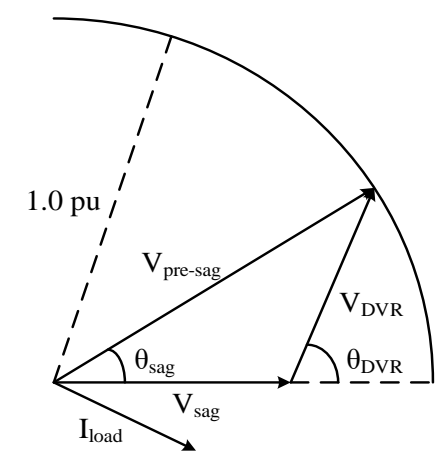

Figure 2. The pre-sag compensation technique

\subsection{Compensation via In-phase}

Figure 3 shows the in-phase voltage compensation method of a DVR. In this method, the DVR injects the voltage magnitude $V_{D V R}$ without the phase angle compensation $\theta_{D V R}$ as in the previous approach. This approach compensates for the reduction of the voltage magnitude only. Therefore, it is suitable for the linear load that does not require any phase angle compensation [19]. When the magnitude of the voltage supply decreases due to the voltage disturbance, the approach provides the missing voltage magnitude $V_{D V R}$ to the load. 


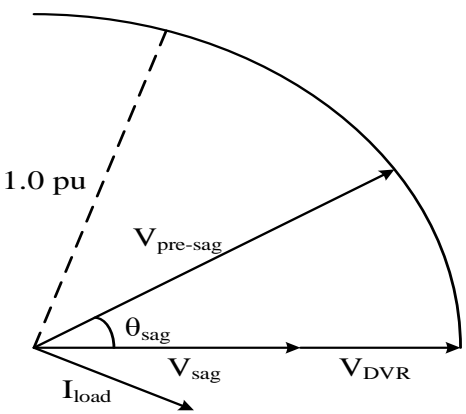

Figure 3. Compensation technique via in-phase

\subsection{Minimum Energy Compensation}

Figure 4 depicts the magnitude and angle representation of the minimal energy compensation method of a DVR. From the figure, the method injects the required voltage magnitude $V_{D V R}$ with the phase angle of $90^{\circ}$ to the load [16]. The system voltage $V_{\text {pre-sag }} \angle \theta_{\text {pre-sag }}$ drops to the $V_{\text {sag }} \angle 0^{\circ}$ following a voltage disturbance in the system. Consequently, the DVR injects the necessary $V_{D V R} \angle 90^{\circ}$ to the system upon detection of the voltage disturbance and raises the voltage to $V_{\text {comp }}$. Although the method does not require active power injection to the system, the injected voltage may require a higher rating transformer and inverter to compensate for the voltage disturbance in the system. As illustrated in the figure, $V_{D V R}$ shown in Figure 4 is relatively higher as compared to the VDVR required for the pre-sag and in-phase compensation method shown in Figure 2 and 3, respectively.

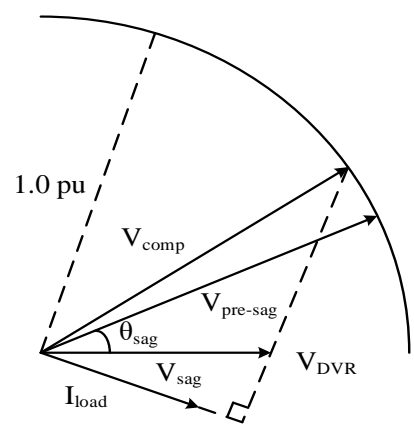

Figure 4. Minimum energy compensation

\section{TYPES OF DVR CONTROL STRATEGIES}

The operation of a DVR is highly depended on its strategies to control the active power and the reactive power in mitigating any power quality issues in the system [22]. As discussed in Section 2, the control strategies of the DVR are focused on the controlling of the VSI [23, 24]. Thus, the discussion in this section is focused on the control strategies of the VSI. There are over a myriad of the VSI control strategies reported in the literature. In this paper, the control strategies of the DVR are segregated into two main categories: linear and non-linear control. The consideration of the DVR control strategies depends on the nature and the sensitivity of the load in the system.

\subsection{Conventional Control}

The conventional control method can be divided into three different categories: feedforward, feedback, and hybrid. The feedforward control is the most common method used in DVR. The method mitigates the power quality issue by determining the difference between the pre-sage and the real-time voltage in the system through an open-loop system [25]. Although it is not as accurate as other control methods, the method is popular due to its simplicity, price, and fast. Thus, it is preferred to mitigate less sensitive and less critical load as compared to other more advanced methods. The feedback method adopts a closed-loop control strategy by comparing the load voltage with the reference voltage [26]. The method outperforms the feedforward method in terms of accuracy in power quality mitigation. However, the method 
is more complicated and has a time delay in providing the required control response. On the other hand, the hybrid control method combines both feedforward and feedback control strategies to utilize the advantages of both methods [27]. The composite control method provides better accuracy of power quality compensation at the expense of the simplicity and the cost of the controller.

\subsection{Artificial Intelligence-based Control}

In practice, it is known that the power system behavior is non-linear in practice. Therefore, the effectiveness of linear control is limited to only a certain operating range. Usually, a conventional controller has covered the application of DVR over a limited operating range. The performance of the linear control of DVR is not enough for the varying operating condition in a higher level of the distribution network. Therefore, the nonlinear control is considered to address this issue. Consequently, there are various nonlinear control methodologies for the DVR that utilized artificial neural network (ANN), fuzzy logic, and space vector pulse width modulation (SVPWM) are reported in the literature. Currently, ANN is being considered in any engineering topic to solve a complex engineering problem in practice. Its ability to replicate the decision-making capability of a human or a complex system is the main highlight of this method. There are several studies reported utilize ANN to provide the nonlinear control for the DVR application [21]. In the report, ANN is able to represent the non-linear correlation between the input and the output without knowing the complex mathematical functions representing the system. The performance of ANN varies with the number of training data and the structure of the neural network considered. Unlike the ANN, the fuzzy logic controller has proved itself in replacing the conventional controller in practice. The fuzzy logic controller allows definite decision-making process based on imprecise or ambiguous data. Researchers in [28] demonstrate the effectiveness of the fuzzy logic controller in the DVR application. In the paper, the fuzzy logic controller is able to decrease the transient overshoot of the VSI. In [29], SVPWM is utilized to eliminate the impact of the negative sequence component of the load voltage on the performance of the DVR. The report shows that the technique successfully mitigates the power quality issue, even the system is unbalanced.

\section{ADVANCEMENT OF DVR}

\subsection{Conventional Sources}

\subsubsection{Using interline dynamic voltage restorer}

Although the DVR is proven to mitigate the voltage disturbance in the system, the cost of replacing the energy storage system is undesirable in a certain situation. The interline DVR is reported in [30-32] to address this issue. Figure 5 shows the typical configuration of the interline DVR. From the figure, it shows that the two closely located DVR shares the same energy storage system to provide the voltage compensation to two different distribution lines. Due to its effectiveness, interline DVR has attracted power system researchers and engineers to conduct further investigation on its application. The study to come out with the optimized design is reported in [33], and the fast control scheme development is reported in [34].

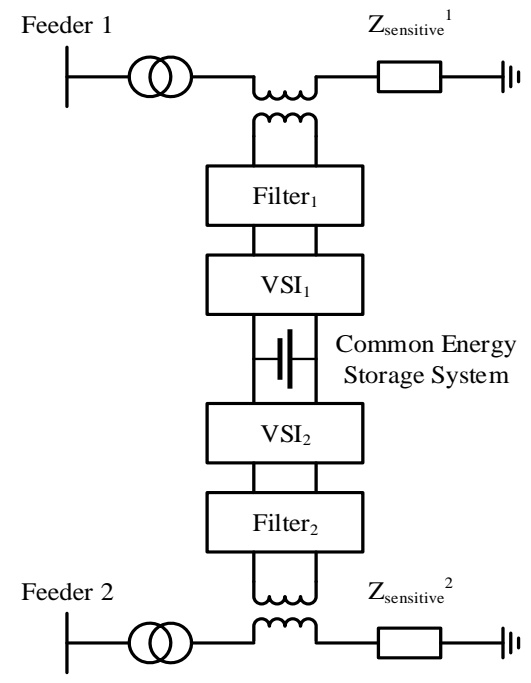

Figure 5. The typical configuration of an interline DVR 


\subsubsection{Development based on SOGI-PLL}

In [35], a control algorithm to generate the reference voltage and current for the DVR application is reported. The method is based on the second-order generalized integrator (SOGI) applied on each phase in the distribution line. The DVR is combined with the D-STATCOM approach as the shunt and series active compensator to compensate the harmonics, sag, and swell in the system voltage and current, respectively. From the report, the SOGI-based algorithm is able to generate the required reference voltage and current from the distorted signals. Researchers in [36] focus on addressing the undesirable performance of the conventional DVR under unbalanced voltage sag condition. The method utilizes a dual SOGI (DSOGI) algorithm to extract the symmetrical components and eliminate the double frequency interference from the measured signal. The approach demonstrates promising performance in mitigating various power quality issues under various types of disturbance such as asymmetric, and symmetric voltage sag and harmonic. On the other hand, second-order - SOGI (SO-SOGI) is reported in [37]. The method aims to achieve fast power quality compensation with and without phase jump at harmonic conditions.

\subsubsection{Other controllers}

Currently, the development of the DVR is active in the literature. There are many advanced controllers have been proposed to address various power quality issues. In [38], a positive and negative sequence extractor (PNSE) is proposed to address the predicament of the conventional SRF-PLL in filtering our negative sequence voltage and harmonics in the power system. The method simplifies the process of the reference generation algorithm in order to restore the voltage following a disturbance in the system. On the contrary, the researchers in [39] report a soft-switching single-phase three-arm DVR to reduce the number of switching during voltage compensation process to improve the reliability of the DVR power circuit. Moving average filter (MAF) based DVR is reported in [33] to extract the positive sequence fundamental component from the distorted supply voltage. The method is proposed to address the performance issue of the conventional DVR in generating an accurate reference instantaneous injected voltage. In [40], a self-tuning filter (STF) is reported with the combination of the PQ control method to improve the performance of the DVR. The method significantly reduces the number of filters required in the DVR design.

\subsection{Renewable Energy Integration}

It is an inevitable trend for the researchers and engineers to consider renewable energy source in the development of technologies in power system studies. The consideration of the renewable energy source to the system possesses huge integration challenges to the power system community. The development of DVR is not excluded from this trend. The researchers in [41] utilize the feedforward vector control algorithm to generate the firing angle for the VSI for the voltage disturbance mitigation. The effectiveness of the proposed method is demonstrated on the actual wind farm measured data at Chinnaputhur substation, India, during the voltage sag and swell event. In [42], a PV-based DVR is reported to improve the power quality following a disturbance in the system. Here, PV plays a bifold role: supplying power to the load and supplying power to the DC-link of the DVR. A switching controller based on wavelet transform is proposed to detect any power quality event and transform the PV system's role into a DVR. A combination of feedforward and feedback control of the DVR is utilized to mitigate the voltage sag during unbalanced fault conditions is reported in [43]. The control of the DVR is vital for the fault ride-through (FRT) capability improvement in the doublyfed induction generator (DFIG) based wind turbine. The report shows that the proposed method is able to compensate for the variance in voltage under both balanced and unbalanced conditions.

\section{CONCLUSION}

As a conclusion, the review of the DVR implementation in the power system is discussed. The typical structure of the power circuit is presented. Each component of the DVR is reviewed in detail. Consequently, the DVR compensation methods utilized in practice are listed and deliberated. This includes the detail explanation of the pre-sag, in-phase, and the minimum energy compensation method. Next, the variance of the control strategies is also discussed in this paper. The discussion includes the operation and critical review of the conventional controller and the artificial intelligence-based controller. Following the discussion on the DVR control strategies, the current advancement of the DVR with the conventional energy sources is discussed as well. The current advancement with renewable energy sources is also reviewed in this paper.

From the discussion, it is recommended to pursue the development of the DVR control circuit, especially for its operation under unbalance voltage disturbance. Although many research have been conducted so far to address this predicament, there is still huge room for improvement in terms of performance and the response time of the controller. In addition, one could also pursue the development of 
the DVR with the integration of the renewable energy source. There are many issues in this topic that require urgent attention from researchers especially for the development of the bifold function of the renewable energy system, and the power quality issues raised following the integration of the renewable energy resources in the conventional power network.

\section{ACKNOWLEDGMENTS}

The authors would like to thank Universiti Tun Hussein Onn Malaysia (UTHM) and Ministry of Education Malaysia for the award that enabled this research under the grant U672 and H208. The author would also like to thank the Ministry of Finance (Iraq) for technical support.

\section{REFERENCE}

[1] A. F. Zobaa and S. H. E. Abdel Aleem, "A new approach for harmonic distortion minimization in power systems supplying nonlinear loads," IEEE Trans. Ind. Informatics, vol. 10, no. 2, pp. 1401-1412, 2014.

[2] B. W. Massoud, A. M., Ahmed, S., Enjeti, P. N., \& Williams, "Evaluation of a multilevel cascaded-type dynamic voltage restorer employing discontinuous space vector modulation," IEEE Trans. Ind. Electron., vol. 57, no. 7, pp. 2398-2410, 2010.

[3] A. P. and D. M. Divan, "Zero-Energy Sag Correctors-Optimizing Dynamic Voltage Restorers for Industrial Applications," IEEE Trans. Ind. Appl., vol. 44, no. 6, pp. 1777-1784, 2008.

[4] A. Pakharia and M. Gupta, "Dynamic Voltage Restorer for C Ompensation of Voltage Sag and Swell : a Literature Review," Int. J. Adv. Eng. Technol., vol. 4, no. 1, pp. 347-355, 2012.

[5] S. M. Aamir, Muhammad, Kafeel Ahmed Kalwar, "uninterruptible power supply (UPS) system," Renew. Sustain. energy Rev., vol. 58, pp. 1395-1410, 2016.

[6] A. G. S. Mahela, Om Prakash, "A review of distribution static compensator," Renew. Sustain. Energy Rev., vol. 50, pp. 531-546, 2015.

[7] R. B. She, Xu, Alex Q. Huang, "Review of solid-state transformer technologies and their application in power distribution systems," IEEE J. Emerg. Sel. Top. Power Electron., vol. 1, no. 3, pp. 186-198, 2013.

[8] A. K. Sadigh and K. M. Smedley, "Review of voltage compensation methods in dynamic voltage restorer (DVR)," in IEEE Power and Energy Society General Meeting, 2012, pp. 1-8.

[9] M. Farhadi-Kangarlu, E. Babaei, and F. Blaabjerg, "A comprehensive review of dynamic voltage restorers," International Journal of Electrical Power and Energy Systems, vol. 92. pp. 136-155, 2017.

[10] S. Zadehbagheri, M., Ildarabadi, R., Nejad, M. B., "Review of Dynamic Voltage Restorer Application for Compensation of Voltage Harmonics in Power Systems," Indones. J. Electr. Eng. Comput. Sci.(IJEECS), vol. 5, no. 1, pp. 58-71., 2017.

[11] \& M. Tamilvanan, G., "Review on AC-AC Converter Based Dynamic Voltage Restorer," Indones. J. Electr. Eng. Comput. Sci.(IJEECS), vol. 2, no. 2, pp. 297-304, 2016.

[12] P. Gakhar and M. Gupta, "A novel control strategy for power quality improvement in grid-connected solar photovoltaic system,” Indones. J. Electr. Eng. Comput. Sci.(IJEECS), vol. 15, no. 3, pp. 1264-1272, 2019.

[13] D. Danalakshmi, S. Bugata, and J. Kohila, "A control strategy on power quality improvement in consumer side using custom power device,” Indones. J. Electr. Eng. Comput. Sci.(IJEECS), vol. 15, no. 1, pp. 80-87, 2019.

[14] A. Ghosh and G. Ledwich, "Compensation of Distribution System Voltage Using Dynamic Voltage Restorer (DVR)," IEEE Power Engineering Review, vol. 22, no. 8. p. 71, 2002.

[15] M. L. Crow, Power quality enhancement using custom power devices. 2002.

[16] A. A. Helal and M. H. Saied, "Dynamic voltage restorer adopting $150^{\circ}$ conduction angle VSI," in 2008 IEEE Electrical Power and Energy Conference - Energy Innovation, 2008, pp. 1-6.

[17] S. Abdul Rahman, P. A. Janakiraman, and P. Somasundaram, "Voltage sag and swell mitigation based on modulated carrier PWM,” Int. J. Electr. Power Energy Syst., vol. 66, pp. 78-85, 2015.

[18] C. Meyer, R. W. De Doncker, Y. W. Li, and F. Blaabjerg, "Optimized control strategy for a medium-voltage DVR - Theoretical investigations and experimental results," IEEE Trans. Power Electron., vol. 23, no. 6, pp. 2746-2754, 2008.

[19] K. R. Padiyar, FACTS Controllers in Power Transmission Distribution. 2007.

[20] M. Vilathgamuwa, A. A. D. Ranjith Perera, S. S. Choi, and K. J. Tseng, "Control of energy optimized dynamic voltage restorer," in Industrial Electronics Society, 1999. IECON'99 Proceedings. The 25th Annual Conference of the IEEE, 2003, vol. 2, pp. 873-878.

[21] K. Perera, D. Salomonsson, A. Atputharajah, and S. Alahakoon, "Automated control technique for a single phase dynamic voltage restorer," in 2nd International Conference on Information and Automation, ICIA 2006, 2006, pp. $63-68$.

[22] R. Omar, N. Abd Rahim, and M. Sulaiman, "Modeling and Simulation for Voltage Sags / Swells Mitigation Using Dynamic Voltage Restorer (DVR)," J. Thereotical Appl. Inf. Technol., pp. 464-470, 2009.

[23] M. R. Banaei, S. H. Hosseini, S. Khanmohamadi, and G. B. Gharehpetian, "Verification of a new energy control strategy for dynamic voltage restorer by simulation," Simul. Model. Pract. Theory, vol. 14, no. 2, pp. 112-125, 2006.

[24] J. G. Nielsen, M. Newman, H. Nielsen, and F. Blaabjerg, "Control and testing of a dynamic voltage restorer (DVR) 
at medium voltage level," IEEE Trans. Power Electron., vol. 19, no. 3, pp. 806-813, 2004.

[25] G. J. Li, X. P. Zhang, S. S. Choi, T. T. Lie, and Y. Z. Sun, "Control strategy for dynamic voltage restorers to achieve minimum power injection without introducing sudden phase shift," IET Gener. Transm. Distrib., vol. 1, no. 5, p. 847, 2007.

[26] S. Ali, Y. K. Chauhan, and B. Kumar, "Study \& performance of DVR for voltage quality enhancement," in 2013 International Conference on Energy Efficient Technologies for Sustainability, ICEETS 2013, 2013, pp. 983-988.

[27] R. A. J. Amalorpavaraj, P. Kaliannan, S. Padmanaban, U. Subramaniam, and V. K. Ramachandaramurthy, "Improved fault ride through capability in DFIG based wind turbines using dynamic voltage restorer with combined feed-forward and feed-back control," IEEE Access, vol. 5, pp. 20494-20503, 2017.

[28] K. C.. Bayindir, A. Teke, and M. Tümay, "A robust control of dynamic voltage restorer using fuzzy logic," in International Aegean Conference on Electrical Machines and Power Electronics and Electromotion ACEMP'07 and Electromotion'07 Joint Conference, 2007, pp. 55-60.

[29] H. Ding, S. Shuangyan, D. Xianzhong, and G. Jun, "A novel dynamic voltage restorer and its unbalanced control strategy based on space vector PWM,” Int. J. Electr. Power Energy Syst., vol. 24, no. 9, pp. 693-699, 2002.

[30] D. M. Vilathgamuwa, H. M. Wijekoon, and S. S. Choi, "Interline dynamic voltage restorer: A novel and economical approach for multiline power quality compensation," IEEE Trans. Ind. Appl., vol. 40, no. 6, pp. 1678$1685,2004$.

[31] M. Shahabadini and H. Iman-Eini, "Improving the Performance of a Cascaded H-Bridge-Based Interline Dynamic Voltage Restorer," IEEE Trans. Power Deliv., vol. 31, no. 3, pp. 1160-1167, 2016.

[32] and K. U. R. Nittala, Ramchandra, Alivelu Parimi, "Application of PST Source based DC Link Restoration for IDVR,” Int. J. Electr. Comput. Eng., vol. 7, no. 3, p. 1103, 2017.

[33] S. Biricik, S. K. Khadem, S. Redif, and M. Basu, "Voltage distortion mitigation in a distributed generationintegrated weak utility network via a self-tuning filter-based dynamic voltage restorer," Electr. Eng., vol. 100, no. 3, pp. 1857-1867, 2018.

[34] C. N.-M. Ho and H. S.-H. Chung, "Implementation and Performance Evaluation of a Fast Dynamic Control Scheme for Capacitor-Supported Interline DVR,” IEEE Trans. Power Electron., vol. 25, no. 8, pp. 1975-1988, 2010.

[35] H. K. Yada, "Operation and Control of Single-Phase UPQC based on SOGI-PLL," 2016 IEEE Int. Conf. Power Electron. Drives Energy Syst., pp. 1-5, 2016.

[36] M. S. Kasyap, A. Karthikeyan, B. V. Perumal, and C. Nagamani, "An effective reference generation and control of DVR using DSOGI-prefilter based PLL," in Proceedings of IEEE International Conference on Circuit, Power and Computing Technologies, ICCPCT 2016, 2016, pp. 1-7.

[37] H. K. Yada and A. S. Kumar, "An SO-SOGI based control for a three-phase DVR under distorted grid conditions including DC offset," in IEEE Region 10 Annual International Conference, Proceedings/TENCON, 2017, vol. 2017-Decem, pp. 3000-3005.

[38] M. S. Kasyap, A. Karthikeyan, B. V. Perumal, and C. Nagamani, "DSC filter based unit vector estimator for reference generation and control of dynamic voltage restorer," in 2016 IEEE 7th Power India International Conference, PIICON 2016, 2017, pp. 1-6.

[39] M. C. Jiang and K. Y. Lu, "Analysis \& design of a novel soft-switching single-phase dynamic voltage restorer," in Proceedings of the 2017 IEEE International Conference on Applied System Innovation: Applied System Innovation for Modern Technology, ICASI 2017, 2017, pp. 861-864.

[40] D. N. Katole, M. B. Daigavane, S. P. Gawande, and P. M. Daigavane, "Analysis, Design and Implementation of Single Phase SRF Controller for Dynamic Voltage Restorer under Distorted Supply Condition,” in Energy Procedia, 2017, vol. 117, pp. 716-723.

[41] A. D. Amalorpavaraj, R. A. J., Palanisamy, K., Umashankar, S., \& Thirumoorthy, "Power quality improvement of grid connected wind farms through voltage restoration using dynamic voltage restorer," Int. J. Renew. Energy Res., vol. 6, no. 1, pp. 53-60, 2016.

[42] D. Divyalakshmi and N. P. Subramaniam, "Photovoltaic based DVR with Power Quality Detection using Wavelet Transform," in Energy Procedia, 2017, vol. 117, pp. 458-465.

[43] A. Rini Ann Jerin, N. Prabaharan, K. Palanisamy, and S. Umashankar, "FRT Capability in DFIG based Wind Turbines using DVR with Combined Feed-Forward and Feed-Back Control," in Energy Procedia, 2017, vol. 138, pp. 1184-1189. 